Archives de sciences sociales des religions

176 | octobre-décembre 2016

Bulletin Bibliographique

\title{
Les Archives, soixantième année
}

\section{La rédaction}

\section{OpenEdition}

Journals

Édition électronique

URL : http://journals.openedition.org/assr/28112

DOI : 10.4000/assr.28112

ISSN : $1777-5825$

Éditeur

Éditions de l'EHESS

Édition imprimée

Date de publication : 31 décembre 2016

Pagination : 13-14

ISSN : 0335-5985

\section{Référence électronique}

La rédaction, «Les Archives, soixantième année », Archives de sciences sociales des religions [En ligne],

176 | octobre-décembre 2016, mis en ligne le 01 janvier 2017, consulté le 24 septembre 2020. URL

http://journals.openedition.org/assr/28112 ; DOI : https://doi.org/10.4000/assr.28112 


\section{Les Archives, soixantième année}

Le présent Bulletin bibliographique marque la soixantième année de la revue. Il y a dix ans, la rédaction avait célébré le cinquantième anniversaire de la revue par un numéro spécial (136) revenant sur sa propre histoire, sa création aprèsguerre au sein du Groupe de sociologie des religions du CNRS, ses développements pluridisciplinaires depuis lors, la diversification de l'objet religieux et l'expansion d'un milieu de recherche international.

Depuis ce numéro de 2006, bien des choses ont bougé dans la revue. Le site internet (assr.revues.org) s'est enrichi de rubriques nouvelles. D'abord, l'annexe électronique du numéro 139 (2012) qui célébrait le centenaire des Formes élémentaires de la vie religieuse; les comptes rendus du chef d'œuvre d'Émile Durkheim depuis sa parution en 1912 sont ici en accès libre. Ensuite, le développement constant d'une rubrique sur l'histoire du Groupe de sociologie des religions avec notamment des éléments biographiques inédits sur ses six pionniers (Gabriel le Bras, Henri Desroche, François-André Isambert, Jacques Maître, Jean Séguy). Enfin, la naissance d'une tribune de débats et de prises de position en direction de l'espace public. Sous l'égide des Éditions de l'EHESS, la revue est diffusée depuis quelques années par l'opérateur Cairn.info qui apporte son savoir-faire électronique et permet par ses recettes le maintien et l'épaississement du volume papier.

Le Bulletin bibliographique à l'origine de la revue n'est pas en reste de cette évolution avec la création de la rubrique "L'atelier des sciences sociales » qui, avec les notes critiques, revient sur l'histoire de nos savoirs, leurs concepts, leurs pratiques, leurs institutions. À ces changements notables pour le lecteur, il faut ajouter ceux relatifs au fonctionnement même de la rédaction. Deux instances président désormais au devenir de la revue : le comité de rédaction, organe éditorial principal qui se réunit bimensuellement ; le conseil scientifique international qui chaque année évalue et oriente la publication. La direction de la rédaction assure le lien quotidien entre ces instances, le secrétariat, les auteurs, les lecteurs ; ses trois membres permanents, auxquels se joint le responsable du bulletin bibliographique, sont élus par l'assemblée générale associant les deux instances, pour quatre ans renouvelables une fois. 
Lors de la dernière assemblée de cette année, le conseil scientifique s'est particulièrement employé à évaluer quatre numéros thématiques en sollicitant pour chacun des experts qualifiés. Il s'agit du numéro 167 sur la sociologie allemande, du numéro 169 sur la philosophie de la religion, du numéro 171 sur les Chrétiens au Proche-Orient, et du numéro 174 sur la «Force des objets - Matières à expériences ». La richesse et la pertinence de propos de ces lecteurs incitent la rédaction à leur consacrer un dossier spécifique dans le prochain numéro du printemps 2017. Manière de célébrer l'anniversaire dans la réflexivité.

La rédaction 